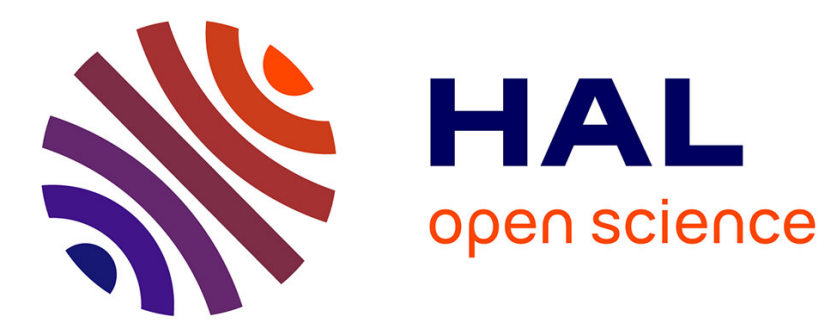

\title{
Image segmentation for phase-contrast hard X-ray CMT of $\mathrm{C} / \mathrm{C}$ composites
}

\author{
Gerard L. Vignoles
}

\section{To cite this version:}

Gerard L. Vignoles. Image segmentation for phase-contrast hard X-ray CMT of C/C composites. Carbon, 2001, 39 (2), pp.167-173. 10.1016/S0008-6223(00)00103-2 . hal-00327612

\section{HAL Id: hal-00327612 \\ https://hal.science/hal-00327612}

Submitted on 16 Oct 2008

HAL is a multi-disciplinary open access archive for the deposit and dissemination of scientific research documents, whether they are published or not. The documents may come from teaching and research institutions in France or abroad, or from public or private research centers.
L'archive ouverte pluridisciplinaire HAL, est destinée au dépôt et à la diffusion de documents scientifiques de niveau recherche, publiés ou non, émanant des établissements d'enseignement et de recherche français ou étrangers, des laboratoires publics ou privés. 
IMAGE SEGMENTATION FOR PHASE-CONTRAST HARD X-RAY CMT OF C/C COMPOSITES

Gerard L. Vignoles

Laboratoire des Composites ThermoStructuraux (LCTS)

UMR 5801 CNRS-SNECMA-CEA-Univ. Bordeaux 1

3, Allée La Boëtie, Domaine Universitaire

F33600 PESSAC

Fax : (33) 556841225

e-mail: vinhola@lcts.u-bordeaux1.fr

\section{ABSTRACT}

In the aim of producing high-quality discretized 3D images of the porous architecture of $\mathrm{C} / \mathrm{C}$ composites, computerized microtomographs have been acquired with synchrotron radiation X-rays. Due to the weak X-ray absorption coefficient of carbon, the result of acquisition at $2 \mu \mathrm{m}$ or $1 \mu \mathrm{m}$ resolution are phase contrast images, not usable as such for the evaluation of geometrical or transport properties. We present here an image treatment algorithm designed to overcome this inconvenient.

\section{KEY WORDS}

A. carbon/carbon composites ; B. chemical vapor infiltration; C. image analysis; D. porosity 


\section{INTRODUCTION}

Carbon/carbon composites are well known high-performance materials for thermostructural applications, such as rocket nozzles or airplane brakes, and their market is in appreciable extension. They are usually produced either by impregnation of a carbon fiber preform by pitches or synthetic mesophases or by chemical vapor infiltration (CVI) $[1,2]$. The need of enhanced product quality and lower production costs has motivated studies concerning their properties of interest either for direct use (mechanical, thermal) or for processing (permeability, diffusivity, specific surface, ...).

One of the possible ways to investigate precisely these properties is to obtain accurate data on the 3D fiber architecture of real preforms at various stages of densification. To achieve such a goal, synchrotron radiation X-ray computerized tomography (CMT) is a powerful tool, whose capability has been well demonstrated $e$. $g$. for $\mathrm{SiC} / \mathrm{SiC}$ composites [3-5]. The resolution available is high enough to isolate single carbon fibers (7-8 $\mu \mathrm{m}$ diameter), and the 3D character of the method yields essential information about the connectivity of the porous and solid phases. It appeared very interesting to extend to $\mathrm{C} / \mathrm{C}$ composites such an investigation method.

It is possible, on the basis of the reconstructed 3D images where the interface between porous and solid phases is visible, to compute the essential geometrical properties [6, 7] and effective transport properties (permeability [8], diffusivity and Knudsen diffusivity [9, 10] as well as mercury penetration curves for the porous phase [11], thermal and electrical conductivity [12], stiffness tensor[13, 14] , ...). It is also possible to perform on such images simulations of the evolution of the microstructure under some constraints, such as matrix deposition or infiltration, and chemical or mechanical degradation.

We present here the starting point for such a methodology, that is, the acquisition and preliminary image treatments required for the use of computational tools on realistic 3D representation of the pore-scale geometry of $\mathrm{C} / \mathrm{C}$ composites. To our knowledge, this is 
the first time that tomographic data of $\mathrm{C} / \mathrm{C}$ composites at fiber-scale is presented and processed.

\section{DATA ACQUISITION}

Images were collected at the ID19 beam line of ESRF (European Synchrotron Radiation Facility). The strong brilliance of the X-ray source enables the selection of a highly monochromatic beam. The energy used was $12 \mathrm{keV}$. Lower energies such as $9 \mathrm{keV}$ and 7 $\mathrm{keV}$, the latter being close to the lowest bound available have also been tested, but the signal/noise ratio was worse. Energy selection is performed using a bent multilayer device, which decreases strongly the acquisition time with respect to a classical double $\mathrm{Si}$ monocrystal device. With successive rotations of the sample, 900 projections, corresponding to 900 angular positions ranging between $0^{\circ}$ and $180^{\circ}$, were acquired each time using a $\mathrm{Gd}_{2} \mathrm{O}_{3} \mathrm{~S}: \mathrm{Tb}$ scintillator, a light amplification setup and a FRELON CCD camera with $1024 \times 1024$ square elements and 14-bit dynamics $[15,16]$. Together with various calibration images, the whole data set corresponding to one tomograph has an approximate size of 2 Gbytes.

The outstanding quality of the beam allows to image samples at a resolution as good as $0.8 \mu \mathrm{m}$ per pixel ; however, a resolution of $1.7 \mu \mathrm{m}$ appeared to be more suited for the examination of $\mathrm{C} / \mathrm{C}$ samples because of the wide size of the representative elementary volume (REV). Accordingly, the studied samples measured less than $2 \mathrm{~mm}$ in diameter. Even though, it is not claimed that 2-mm width images do contain a C/C composite REV. From the set of calibrated projections, a filtered backprojection routine is applied, which allows to rebuild 3D attenuation images of the sample ${ }^{\mathbf{1}}$. An example of a slice of a reconstructed data set is shown at fig. 1 .

The problem that arises specifically when imaging $\mathrm{C} / \mathrm{C}$ composites is linked to the low absorption coefficient of carbon at the used energy, together with the important coherence

\footnotetext{
${ }^{1}$ The program that has been used is Volumic, developed by CREATIS (INSA Lyon/CNRS), with kind permission of F. Peyrin.
} 
of the beam, and the order of magnitude of the resolution. In such conditions, the X-ray beam is much more sensitive to phase shifts than to intensity absorption [17]. When the detector plane is placed roughly at one centimeter behind the sample, the image obtained after reconstruction displays an enhancement of the void-solid interface under the form of a bright-dark double band, while the interior of both phases are of approximately the same mean grey level. The double band is the result of an interference between the coherent rays passing, close to the interface, through both phases, one of which (carbon) induces a phase shift. If the detector were placed at longer distances behind the sample, Fraunhofer fringes would appear. It is even possible to use this phenomenon to obtain 3D holographic images of a medium [18].

\section{IMAGE TREATMENT}

If phase contrast allows the immediate production of understandable images, it is not suited for subsequent computations. What a software needs is something like a density field, i.e. the value of density at any point $(\mathrm{x}, \mathrm{y}, \mathrm{z})$ inside the image (or in a simpler way, the knowledge that any given point lies in the void or the solid phase), or at least a description of a continuous void-solid interface (i.e. segmentation). The first issue is obviously not given by phase contrast imaging, while the second is not attainable in practice. When two interface parts are too close one to the other, their phase-contrast double layers interfere with each other, leading to a local destruction of these double layers. For example, this artifact does not appear when imaging isolated convex inclusions inside a matrix.

Nevertheless, the important information is contained inside the phase-contrast image, since for most of the interface, the bright layer is always on the same side of the interface (e.g. the solid side) and the dark layer lies always on the other. A variety of methods may be designed to answer the following question : for any point (voxel) of the discretized image, what is the phase it lies in?

Prior to any of them, some preliminary image segmentation is needed. A double thresholding treatment separates the voxels into three groups : 
- The black (dark) voxels, which are already considered to lie in the solid phase ;

- The white (bright) voxels, which are considered to lie in the void phase ;

- The grey voxels, for which the information has to be obtained.

At this point, the information is still stored on 8-bit words for each pixel. This unoptimal storage proves to be useful during posterior treatments, when the pixels may be temporarily set to an unused color (instead of creating extra memory buffers for copying selected parts of the image).

If some noise is present inside the image, it is possible that some isolated groups of black or white voxels appear far from the true interface. Accordingly, we do some "image cleaning" by removing (i.e. painting in grey) all groups of black or white voxels which are only surrounded by grey voxels.

Now it is possible to focus the attention on the grey voxels, which have to be turned black or white. 
One possible method is to use a percolation algorithm :

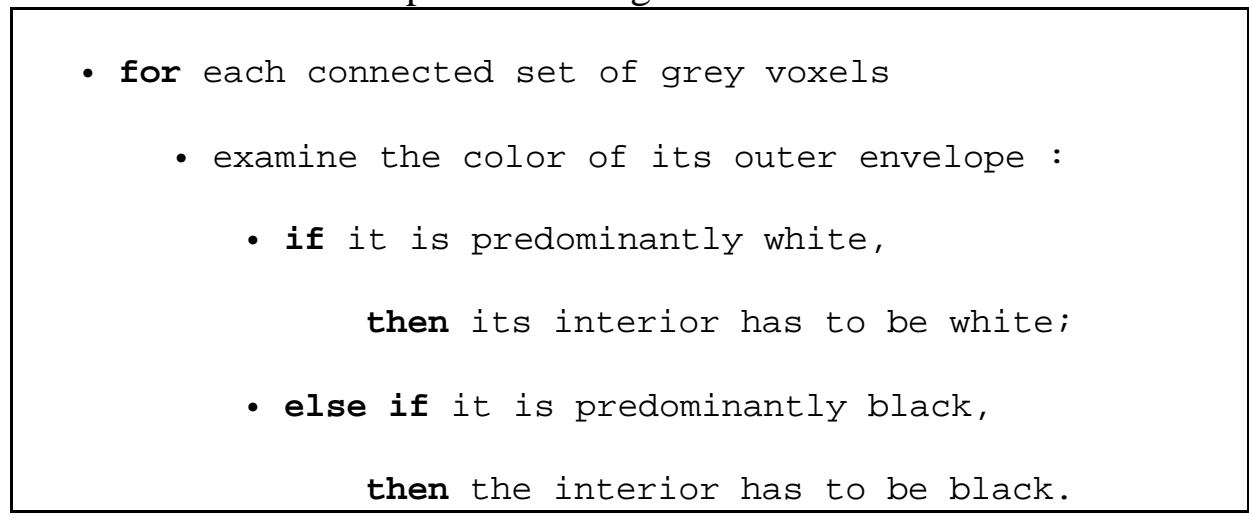

Algorithm 1

This algorithm requires the use of a front propagation routine in order to isolate each connected grey subset, much like a "magic wand" tool. The mean color of the envelope pixels is updated whenever a new envelope pixel is visited. During this invasion routine, the selected pixels are set to yet unaffected colors ; they are then set back to their original colors or to the newly determined black or white value. To optimize this step, record is made of the bounding box containing any connected subset and its envelope.

Another possible treatment is a kind of mathematical dilation, where the black and white subsets are allowed to dilate only inside the grey regions :

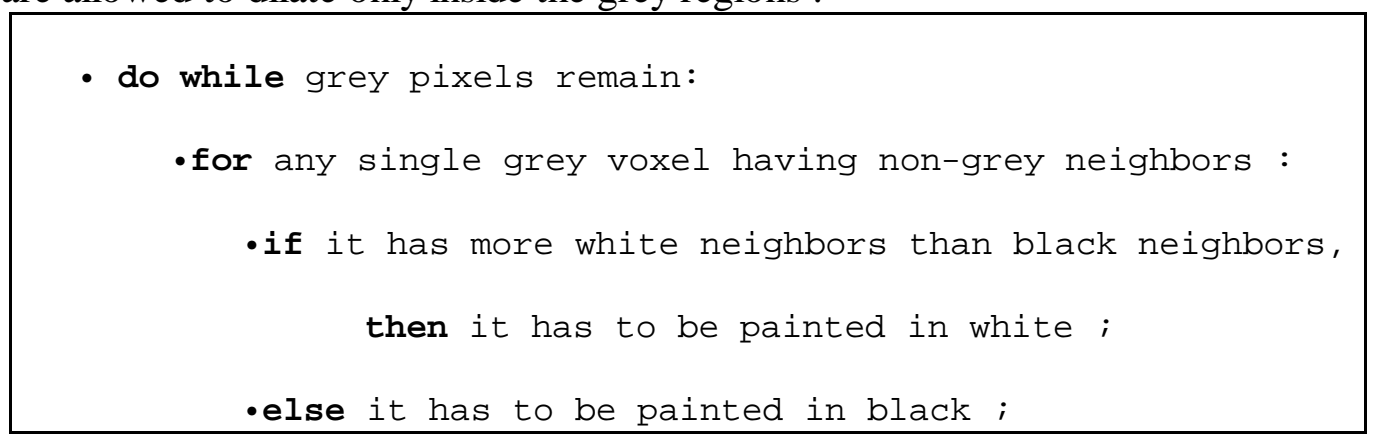

Algorithm 2

This very light algorithm requires a greater number of iterations until completion, so the memory spares have been done at the expenses of computational time. It is a version of an algorithm known as "hysteresis" [19]

After having applied one of these algorithms, the image is fully binary. However, some closed porosity remains, which is removed using a classical percolation algorithm . It is 
also possible to use a mask and recover the exact grey-level values of the pixels which touch the interface, in order to use subsequently accurate surface tesselation procedures[10].

\section{RESULTS}

The image treatment sequence has been performed on a 200x200x50 pixel $^{3}$ sub-sample of a tomograph taken at $2 \mu \mathrm{m}$ spatial resolution (see one slice in fig. 1), or on smaller subimages for rapid checking. Preliminary segmentation has been made using the values exhibited in fig. 2, which isolate a single histogram peak for the retained grey zone. The result of the double threshold is in fig. 3, and fig. 4 is obtained after removal of "isolated" black or white stains (that is, not touching respectively any white or black voxel).

From this point, Algorithm 1 alone has proved to be unstable with respect to the image size ; that is, it works correctly on some subimages, but not on the whole image. The reason for it is that in some image part there exists a possibility of connecting together grey regions which lie in the void phase and in the solid phase. 26-connectivity was worse than 6-connectivity, for evident reasons.

Algorithm 2 is capable of producing alone correct results in 6-connectivity (see figs. 5, 6 and 7), but induces some "hairline" artifacts (circled region at fig. 7)[20]. They correspond to interface regions where the expected black/white pattern is not complete. To remove these as much as possible, a compromise is to apply only one or two dilations according to Algorithm 2 (fig. 6), followed by the application of algorithm 1. Indeed, the preliminary dilations have the effect of separating grey regions lying in opposite phases. This makes possible the use of algorithm 1, which does not introduce localized artifacts of algorithm 2. Figs. 8 and 9 (after removal of closed porosity) show the result of such an approach, which is better than fig. 7 .

Fig. 10a is a 3-dimensional rendering of the image at final stage of treatment. It is clearly apparent that an acceptable geometrical description has been obtained. For instance, coated single fibers are clearly seen. Some of them were broken when the preform had 
been woven : the shape of their tips appears as "rounded off" by the deposition process (see fig. 10b), which is known to correspond to an important diffusion/reaction ratio in the gas-phase elaboration conditions [21].

\section{CONCLUSION AND PERSPECTIVES}

An image treatment sequence has been designed to extract pertinent information from $\mathrm{C} / \mathrm{C}$ tomographs displaying a phase contrast structure enhancing the void/solid interface. Two algorithms, one based on mathematical dilation and the other on the examination of the envelope of undetermined connected subsets, have been worked out and used, allowing to retrieve the belonging of any pixel to the void or solid phase.

Phase contrast images, after this treatment, are now suited for subsequent physicochemical computations at pore-scale. This is an essential issue for the study of $\mathrm{C} / \mathrm{C}$ composites. Two complementary research directions may be taken : i) the direct simulation of physico-chemical processes, and ii) the computation of somewhat elaborate geometrical properties such as skeletonization and medial axis analysis.

This image treatment sequence should be of interest for many other kinds of materials, like water-containing and other low-density compounds, multiphase materials displaying low absorptivity differences between their constitutive phases, and even biological structures.

The work presented here has been developed under the general approach of the thematic group CM3D in Bordeaux, which intends to apply similar methods to many other fields such as sandstone diagenesis and sintering of ceramics.

\section{ACKNOWLEDGEMENTS}

The financial support of both Conseil Régional d'Aquitaine and SEP, division de SNECMA is acknowledged. 
The author is indebted to the ID 19 team of ESRF headed by José Baruchel, and especially to Elodie Boller and Peter Cloetens for data acquisition. Reconstructions from crude acquisition data has been performed with the "Volumic" software with kind permission of Françoise Peyrin, CREATIS, INSA, Lyon. 


\section{FIGURE CAPTIONS}

Fig. 1 : Image extracted from one slice of a reconstructed 3D image of a C/C partially densified preform obtained by synchrotron X-ray CMT. Resolution is $1.7 \mu \mathrm{m}$ per pixel. Size is $200 \times 200$ pixels.

Fig. 2 : Histogram of image 1, and values for double thresholding.

Fig. 3 : As fig. 1 after double thresholding.

Fig. 4 : As fig. 3, after removal of isolated stains.

Fig. 5 : As fig. 4 , after one dilation of black and white sets.

Fig. 6 : As fig. 4 , after 2 dilations of black and white sets.

Fig. 7 : As fig. 4, after all dilations of black and white sets. Note the artifact at the upper right corner.

Fig. 8 : As fig. 6, after invasion and coloring by the skin.

Fig. 9 : As fig. 8 , after removal of closed porosity.

Fig. 10 : a) 3-D rendering of the treated sample. b) Detail of a rounded fiber tip (circled). 


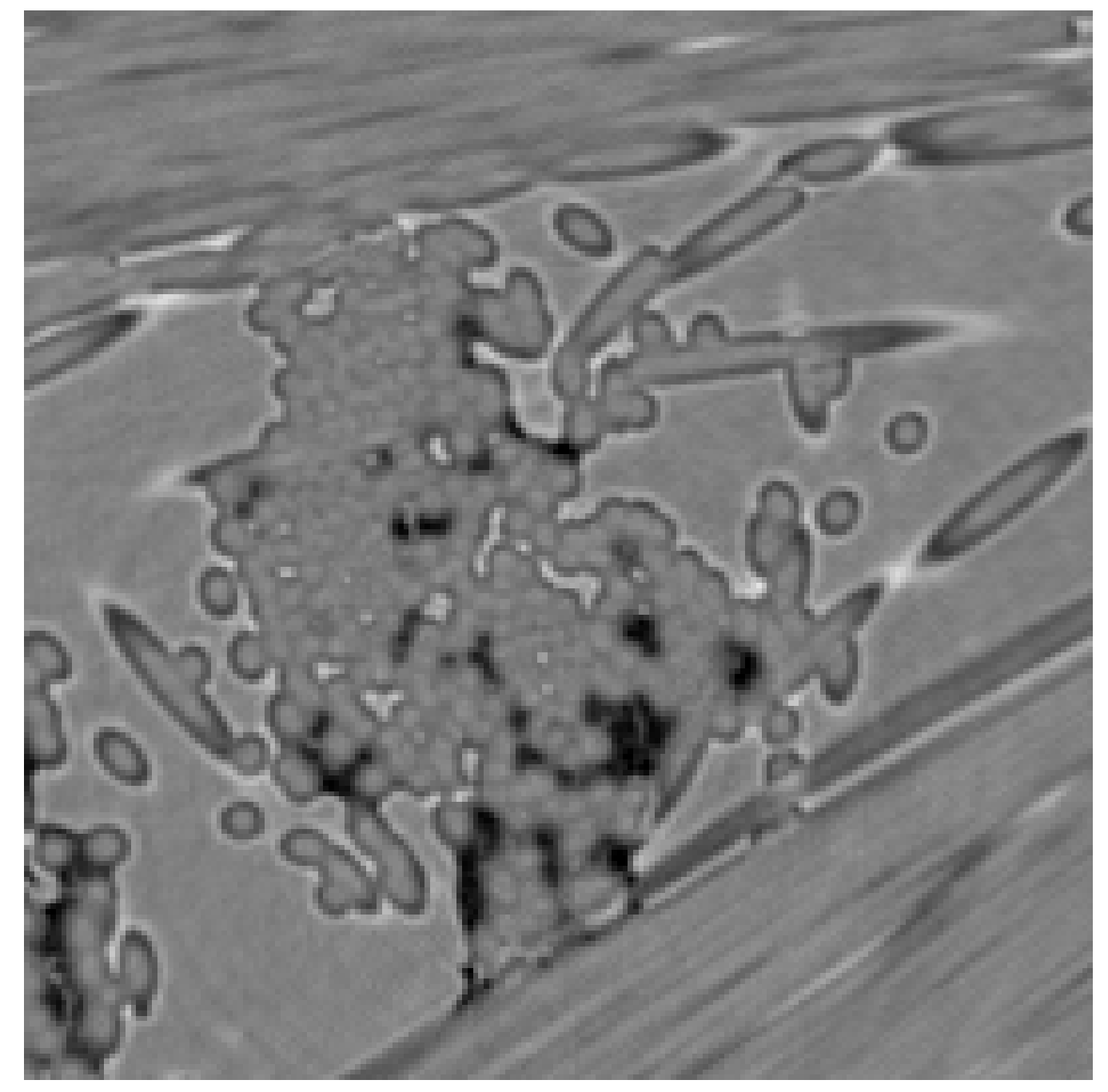

Fig. 1. 


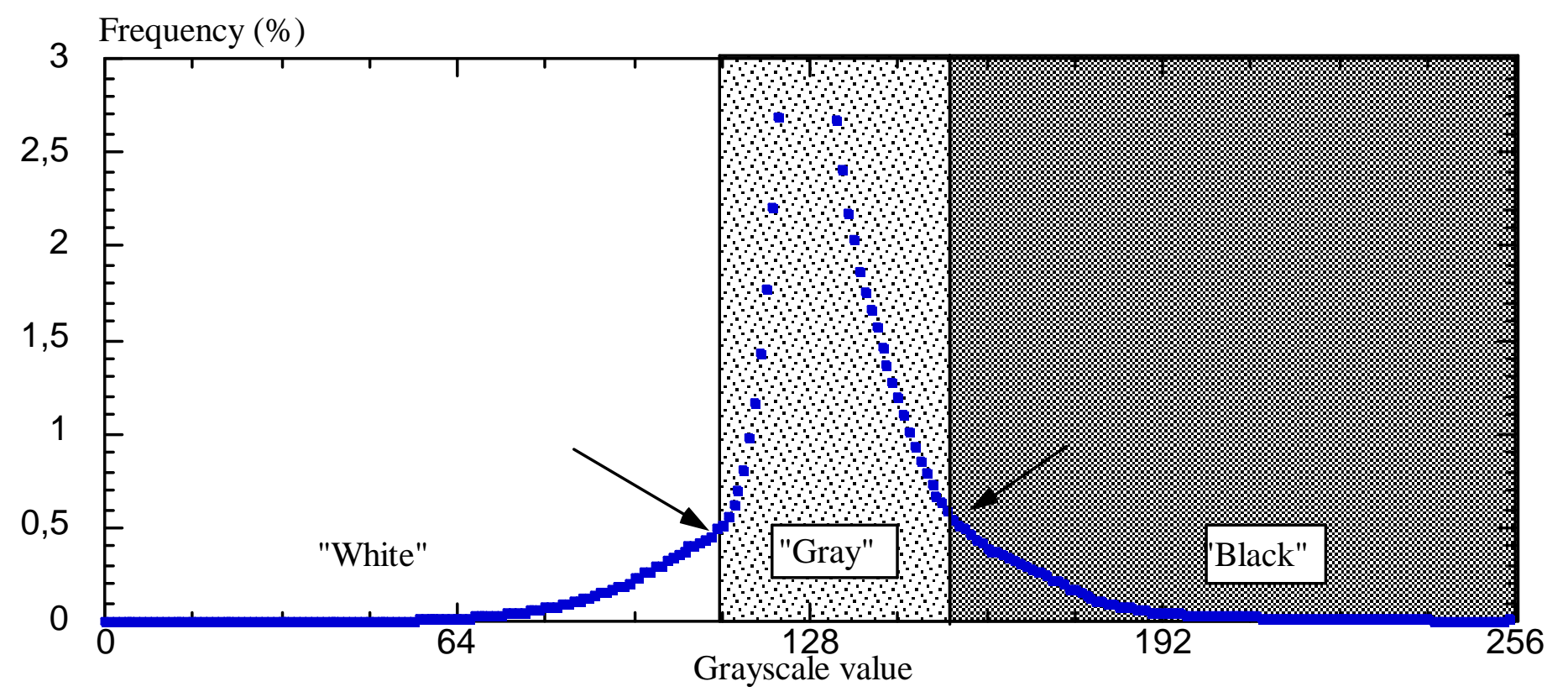

Fig. 2. 


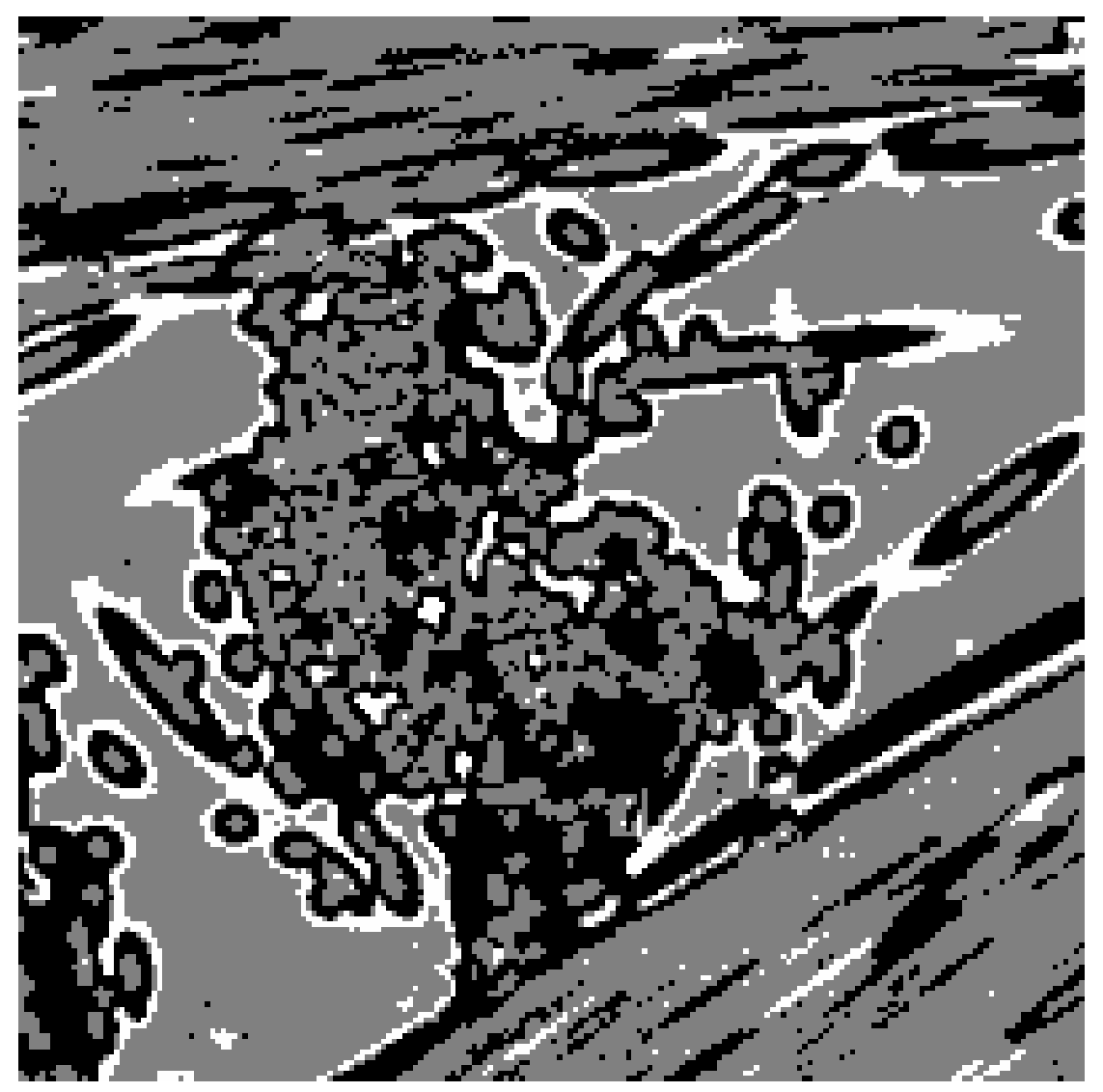

Fig. 3. 


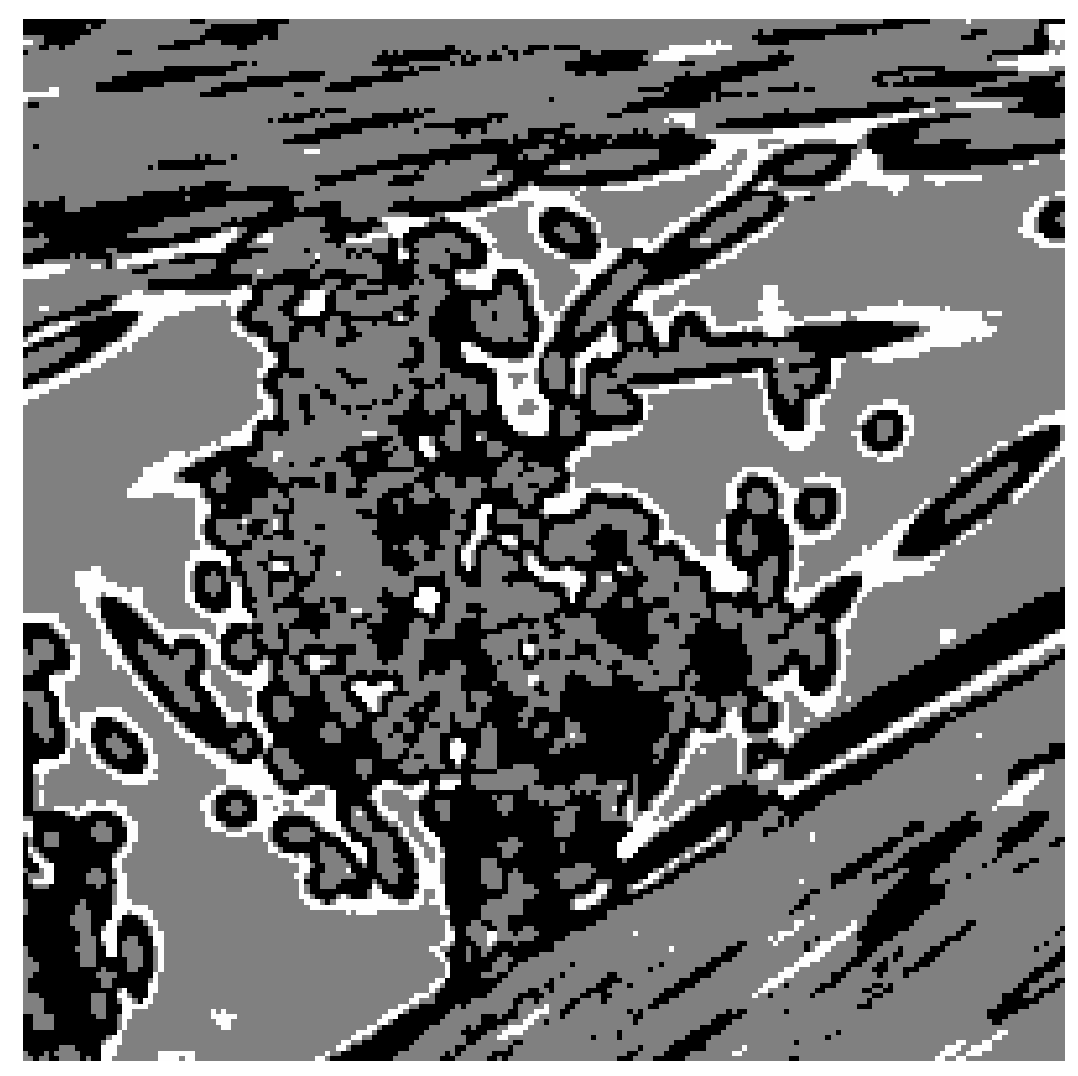

Fig. 4. 


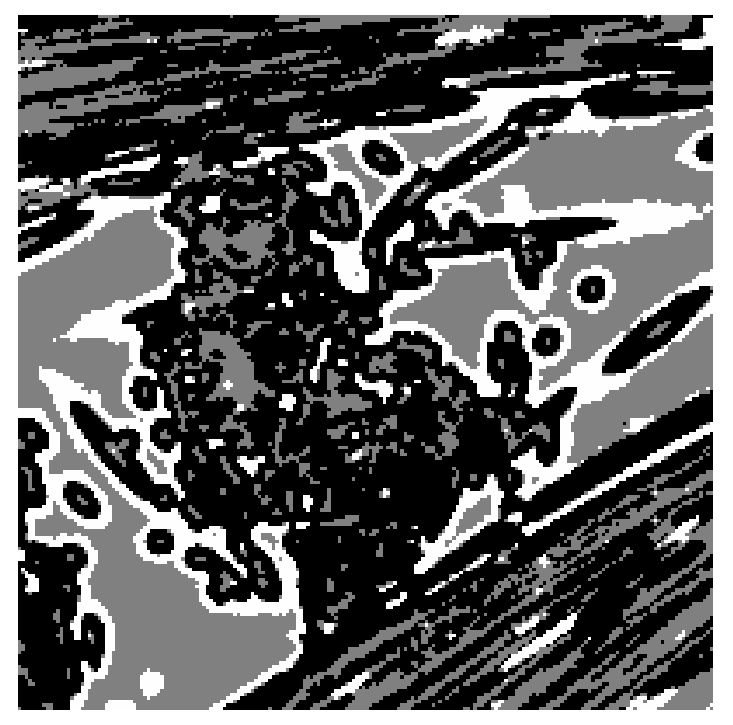

Fig. 5.

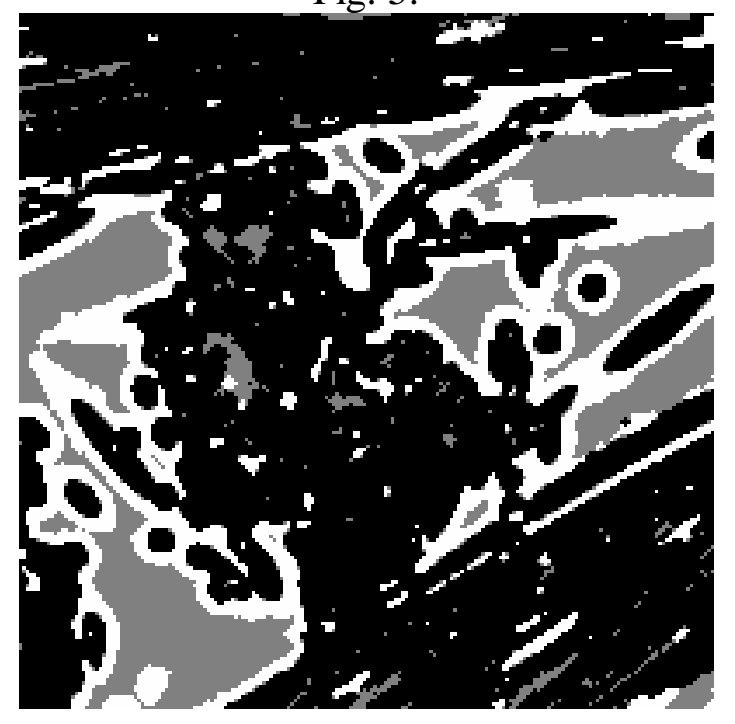

Fig. 6.

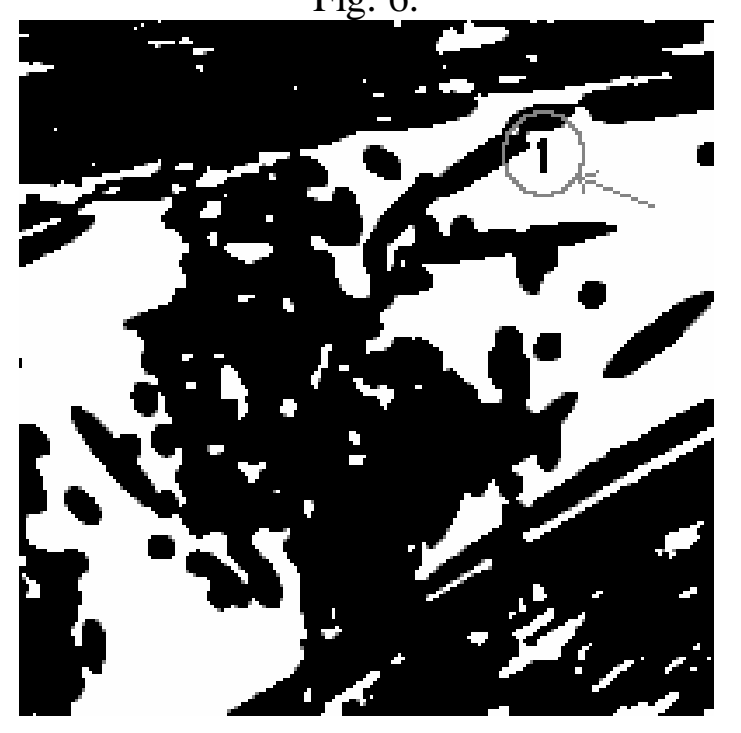

Fig. 7. 


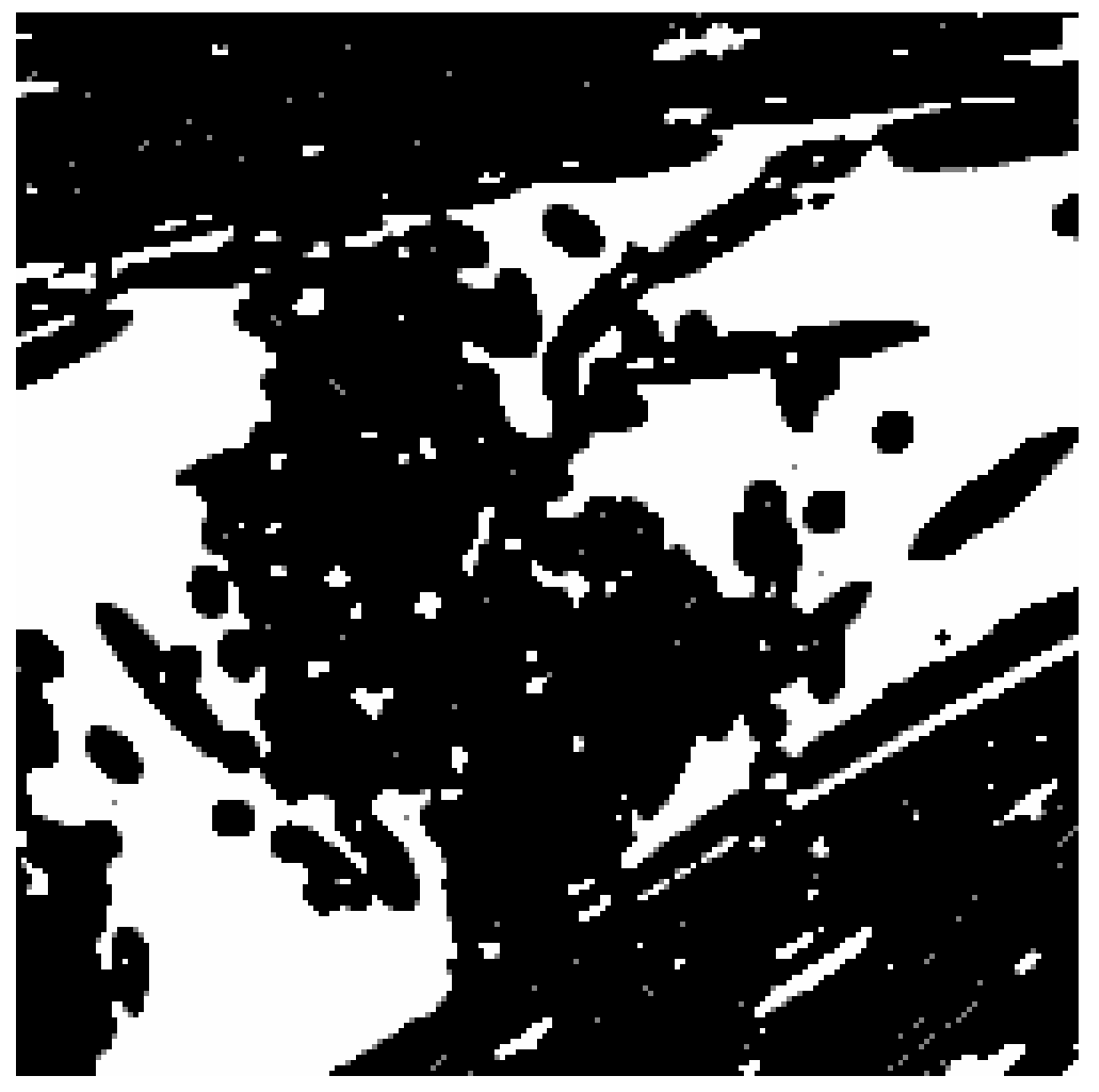

Fig. 8. 


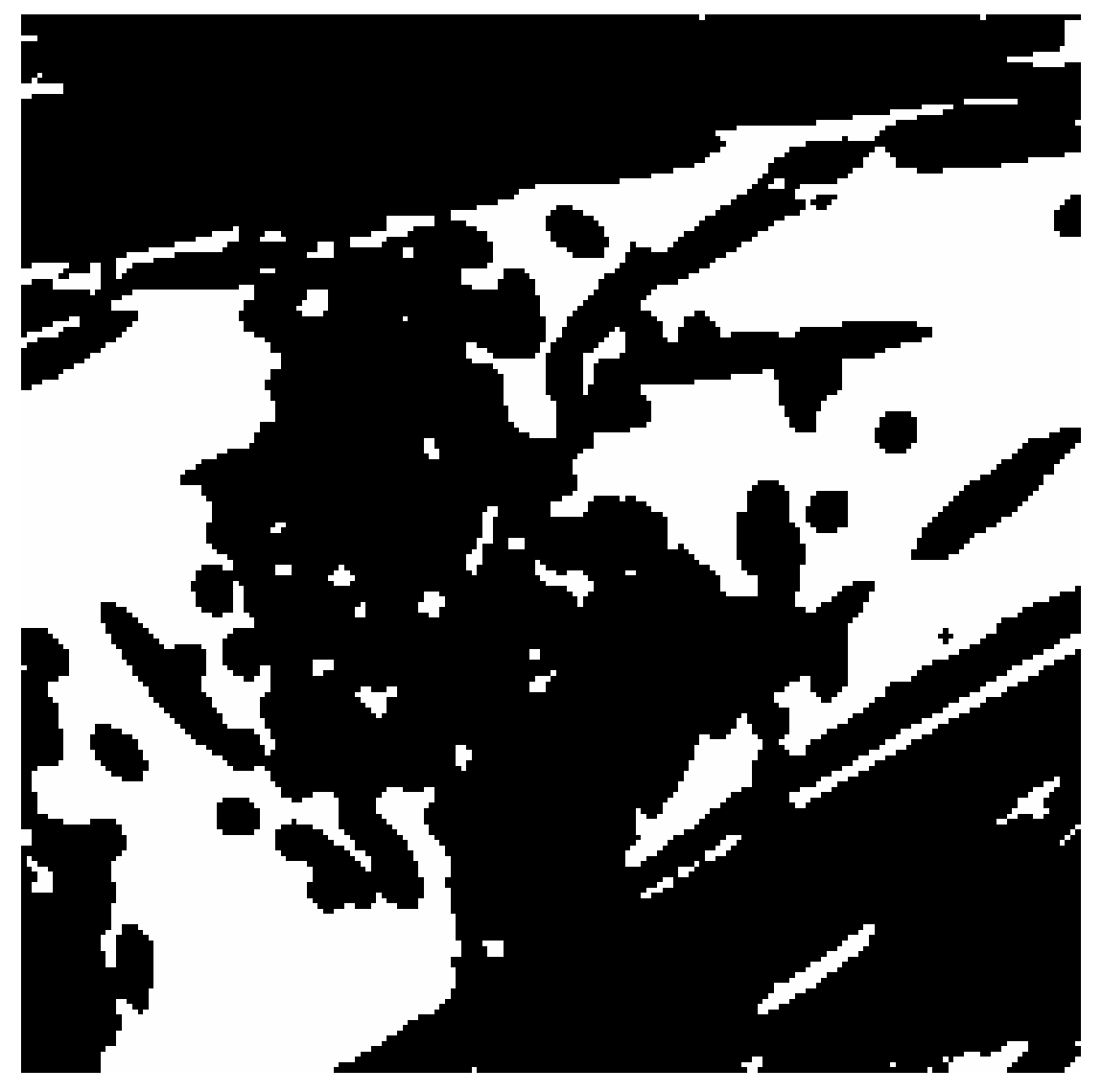

Fig. 9. 


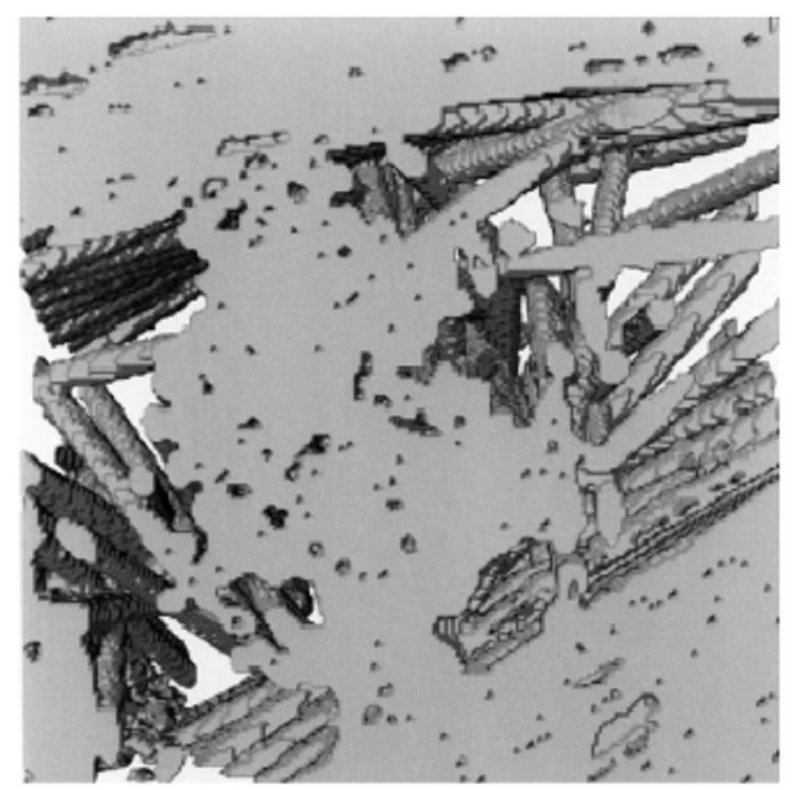

a)

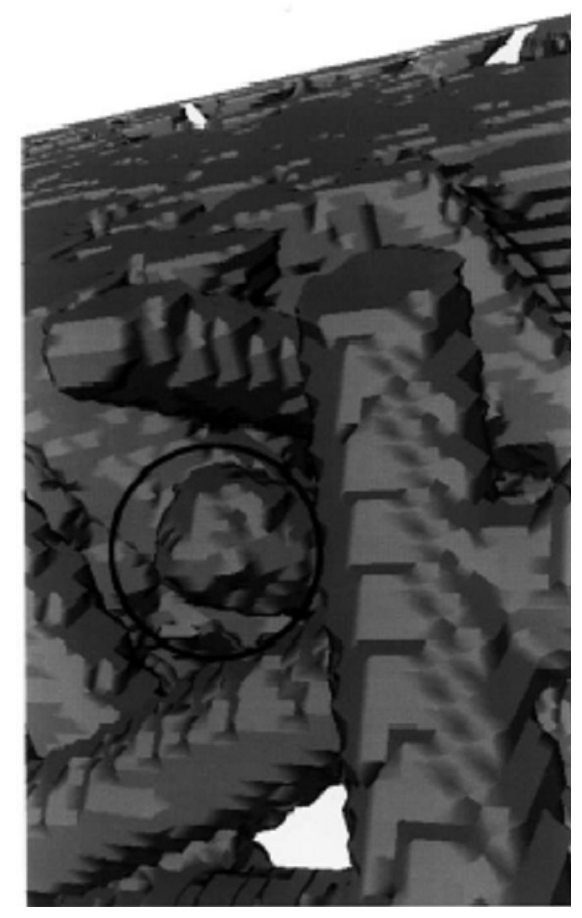

b)

Fig. 10. 


\section{REFERENCES}

1. Naslain R. Key Engineering Materials, CSJ Series - Publications of the Ceramic Society of Japan Vol. 164-165, Bern, Switzerland: Trans Tech Publications, 1999. p. 3-8. 2. Naslain R, Langlais F. In Tressler RE, Messing GE, Pantano CG, Newnham RE, editors. Tailoring multiphase and composite ceramics, Mat. Sci. Res. Vol. 20, 1986. p. 145.

3. Kinney JH, Haupt DL, Breunig TM, Nichols MC, Starr TL, Stock SR. 17th Annual conference on Composites and Advanced Ceramic Materials. Cocoa Beach, FL, 1993. In Ceramic Engineering \& Science Proceedings, 1993; 14 (9-10). p. 1028-1037.

4. Kim J, Liaw PK, Hsu DK, McGuire DJ. 21st Annual conference on Composites, Advanced Ceramics, Materials, and Structures. Cocoa Beach, FL, 1997. In Ceramic Engineering \& Science Proceedings, 1997; 18 (4). p. 287-296.

5. Kinney JH, Breunig TM, Starr TL, Haupt D, Nichols MC, Stock SR, Butts MD, Saroyan RA. X-ray Tomographic Study of Chemical Vapor Infiltration Processing of Ceramic Composites. Science 7 May 1993; 260: 789-792.

6. Lindquist W, Lee SM, Coker D, Jones K, Spanne P. Medial axis analysis of threedimensional tomographic images of drill core samples. J. Geophys. Res. 1996; 101B:8297-8310.

7. Lee S-B, Stock SR, Butts MD, Starr TL, Breunig TM, Kinney JH. Pore geometry in woven fiber structures : $0^{\circ} / 90^{\circ}$ plain-weave cloth layup preform. J. Mater. Res. 1998; 13(5):1209-1217.

8. Bernard D. In Gambolati G, Verri G, editors. Advanced methods for groundwater pollution control, Int. Centre for Mechanical Sciences Vol. Wien - New York: Springer Verlag, 1995. p. 9-24.

9. Vignoles GL. Modelling binary, Knudsen, and transition regime diffusion inside complex porous media. J. de Physique IV 1995; 65(1):159-166.

10. Blasi P, Le Saëc B, Vignoles G. In Dorsey J, Slusallek P, editors. Rendering Techniques '97 : Proc. 3rd Eurographics Workshop on Rendering, St-Etienne, France, Wien: Springer Verlag, 1997. p. 297-308. 
11. Hazlett RD. Simulation of Capillary-dominated Displacements in Microtomographic Images of Reservoir Rocks. Transport in Porous Media 1995; 20(1-2):21.

12. Quintard M, Whitaker S. Transport in ordered and disordered porous media : volumeaveraged equations, closure problems, and comparison with experiment. Chem. Eng. Sci. $1993 ; 48: 2537$.

13. Poutet J, Manzoni D, Hage-Chehade F, Jacquin CG, Boutéca MJ, Thovert J-F, Adler PM. The effective mechanical properties of reconstructed porous media. Int. J. Rock. Mech. Min. Sci. \& Geomech. Abstr. 1996; 33(4):409-415.

14. Bigaud D, Hamelin P. In Procs. International Conference on Composite Structures. Paisley, Scotland, 1997.

15. Salomé M, Peyrin F, Cloetens P, Baruchel J, Spanne P, Suortti P, Laval-Jeantet A-M. Assessment of bone micro-architecture using 3D computed microtomography. ESRF Newsletter April 1997; (http://www.esrf.fr/info/science/newsletter/Apr97/Page3.htm). 16. Labiche JC, Segura Puchades J, van Brussel D, Moy JP. ESRF Newsletter March 1996; 41.

17. Cloetens P, Barrett R, Baruchel J, Guigay JP, Schlenker M. Phase objects in synchrotron radiation hard-X-ray imaging. J. Phys. D : Appl. Phys. 1996; 29:133-146. 18. Cloetens P, Guigay J-P, De Martino C, Salomé M, Schlenker M, D. VD. Quantitative aspects of coherent hard X-ray imaging : Talbot images and holographic reconstruction. Proceedings SPIE 1997; 3154:72-82.

19. Canny JF. In Fischler M, Firschein O, Fischler MA, editors. Readings in Computer Vision, Vol. Los Angeles: Morgan Kaufman, 1987. p. 184-203.

20. Hodgetts MA, Fallside F. In Procs. 4th Intl. Conf. on Image Processing and its Applications. Cambridge University, UK. p. 307-310.

21. Schröder K-W, Schlote J, Hinrich S. Simulation of step coverage in chemical vapor deposition process. J. Electrochem. Soc. 1991; 138(8):2466-2468. 